years. Many of the maps have marked new departures in cartography, and this is certainly true of the latest addition to the series depicting towns and their hinterlands*. It is obvious that every market town exercises a considerable influence on the surrounding countryside, but this 'hinterland' is difficult to define and to delimit. It has little or no connexion with administrative units, and yet is obviously of great importance in planning the social services to be pro. vided by the urban centre as well as of no little interest in the organization of retail trade and services.

The criterion here adopted owes much to the pioneer studies of F. H. W. Green, and is that of bus services. A town or village is defined as a centre if it has operating from it at least one bus service which serves no place larger than itself. The centres with populations over three thousand (using the 1951 Census) are represented by an orange circle proportional to the population, surrounded by a green circle proportional to the population of the hinterland. Firm lines mark-perhaps with a firmness their shadowy nature does not warrant- the boundaries of the hinterlands. In general terms, the people living within a given hinterland normally visit the centre shown for shopping, entertainment, cultural and professional services.

So much of the extensive programme of town and country planning to which Britain is committed is of necessity based upon very slight factual knowledge, and such attempts as are illustrated by this map to introduce a scientific objectivity are entirely praiseworthy. Though the centres are smaller and the hinterlands are larger in the sparsely populated parts of the country, what strikes one is the relatively even spacing of the centres. In days of old when people walked to market (or the richer rode on horseback), the effective hinterland of a market town had a radius of about four miles. It still seems to be only about six miles. Over much of England the centres tend thus to be ten to twelve miles apart. It is more in Wales and Scotland.

\section{Dudley Stamp} * Local Accessibility : the Hinterlands of Towns and Other Centres as determined by an Analysis of Bus Services. Sheet 1: Scotian and $N$. Fingland. Sheet 2 : the Remainder of England and Wales. Compiled by the Ministry of Housing and Local Government from Information supplied by the Bus Operators and the Ministry of Transport and Civil Aviation. (Chessington, Surre

\section{LIBRARIES OF THE DYESTUFFS DIVISION OF IMPERIAL CHEMICAL INDUSTRIES, LTD.}

\section{NEW BUILDING AT BLACKLEY}

$\mathrm{T}$

HE new library building of the Dyestuffs Division, Imperial Chemical Industries, Ltd. was opened at Blackley, Manchester 9, on June 27 by Mr. Clifford Paine, development director of Imperial Chemical Industries, Ltd., and until recently chairman of the Division. Mr. Paine said that a first-class scientific library is the core of a research organization and expressed the hope that the new building will provide the conditions which will stimulate creative work in the minds of those who are expected to make the discoveries of to-morrow. Although the value of library and related services has long been recognized in the Dyestuffs Division, it is only with its removal in May 1955 to the present building that the Main Library of the Division has been housed in premises worthy of its holdings and the services provided. The Divisional libraries hold a total of nearly forty thousand bound volumes (of which about half are periodicals), together with about twenty thousand pamphlets and miscellaneous publications, some fifteen hundred bound volumes of patent specifications and several hundred unbound specifications. About half the total collection is housed at Hexagon House, Blackley, where the collection in organic chemistry and related subjects is probably one of the finest in Great Britain. More than a thousand current periodicals are taken, and about half of these are bound.

The present library collection goes back to the days before the formation of Imperial Chemical Industries, Ltd., the nucleus being provided by the libraries maintained by Levinstein, Ltd., of Blackley, and British Dyes, Ltd., of Huddersfield; the bulk of the latter forms the nucleus of the branch library now maintained at Huddersfield, just as that of Scottish Dyes, Itd., later formed the nucleus of the Works Library at Grangemouth, Stirlingshire. In 1925 the Levinstein collection was moved into the block of buildings which now houses the administrative offices of the Dyestuffs Division, being transferred in 1932 to a new wing specially designed to be permanent quarters. This was evacuated on the outbreak of war in 1939 and, after two years in makeshift premises in a local school, the Library was moved into a temporary single-story building adjacent to the Research Department of the Division. The library organization includes a Records and Reports Section which is responsible for the care of most of the Dyestuffs Division's permanent technical and commercial records and reports, of which about a hundred and fifty thousand different documents are at present filed; a Technical Section, which collects and indexes technical data of various kinds; and a Commercial Library, not housed in the new block, but situated adjacent to the Sales Departments in Hexagon House, which also collects commercial data.

The new library building, which connects two existing research blocks, has four main floors and a top floor that is occupied by a lecture theatre seating 156, most of the seats being provided with writing flaps. Of the total floor area of 17,000 sq. ft., 2,500 sq. ft. is occupied by the lecture theatre and ancillary rooms, 3,000 sq. ft. by the ventilating plant, corridors, lift, etc., and 2,000 sq. ft. by the basement store. The Main, Technical and Patents Libraries and library offices occupy 5,500 sq. ft., the Records and Reports Section 1,600 sq. ft., and general administration and workshop $1,200 \mathrm{sq}$. ft. All are characterized by light and spaciousness; the Main Library, on the first floor, measuring $75 \mathrm{ft}$. by $45 \mathrm{ft}$., has good north and south lighting and seating accommodation for forty. Shelving and reading space are arranged in the form of alcoves, and shelving and furniture are in walnut, many of the individual tables provided having built-in table easels.

The Techureal Library on the ground floor has about one-third the area of the Main Library, and seating accommodation for twelve. It is equipped with cream-coloured steel adjustable shelving, and tables and chairs in natural oak. Adjacent to it is a workshop equipped for repair work on books and pamphlets, cover and case making, report binding and parcelling, and a small dark room off the work- 
shop is equipped with photocopying apparatus. Off the Main Library, on the first floor, there is a small room for storing and reading microfilms. On the second floor there are the main files of the Records and Reports Section, the index room and the collection of British and foreign patent specifications.

\section{ENERGY VALUE OF FOOD}

$\mathrm{T}$ O determine the number of calories that a known weight of food will give when it is burned in a bomb calorimeter is relatively simple; but to assess accurately the number of calories that the animal body can derive from that food presents several problems which have not yet been satisfactorily solved. The subject was discussed at a symposium arranged by the Scottish Group of the Nutrition Society and held at the Hannah Dairy Research Institute, Kirkhill, Ayr, on April 30. The morning session was devoted to methods of assessing the energy of feeding-stuffs for animals, and the afternoon session to the problem as it concerns food for man. At intervals during the day some of the work in progress at the Hannah Institute on the production and emission of heat by farm animals was demonstrated.

In introducing the subject the chairman, Prof. R. C. Garry (University of Glasgow), stressed the danger of regarding food simply as though it were fuel for a machine. Food is much more than fuel, and the animal body much more than a machine. Food has to build, repair and maintain the fabric of the body as well as supply it with energy for work, and the body, unlike the machine, processes its fuel in digestion, absorption and metabolism. The content of minerals, vitamins and other substances present may all affect the energy value of the food by influencing the well-being of the animal, and in man the matter is still more complicated since social habit, beliefs and prejudices may all play a part. The chemistry of a foodstuff must be thoroughly understood : in time the biochemical processes by which energy is liberated from it will be elucidated; but it will still be essential to consider the living animal as a biological entity.

The first paper of the morning session was a joint communication by K. L. Blaxter and N. McC. Graham, who first dealt briefly with the history of methods of evaluating foods as sources of energy for livestock. They pointed out that reliable values are needed for planning livestock production both at farm and at national level, since on such values depend in large measure the animal product output of farming as a whole and estimations of the quantities of feedingstuffs that must be imported. The second point they made was that measures of the energy value of foods are biological measures and cannot be expected to have the precision usually associated with the physical term 'calories' in which they are presented. Their statement that the efficiency of an animal in utilizing its food necessarily influences the nutritive value of the food it consumes emphasized this point, and was a theme that recurred time and again during the subsequent discussions.

Referring to the different ways in which the energy value of food for cattle is expressed, Blaxter and Graham emphasized the fact that, in order to estimate the value in torms of body storage of energy or in terms of energy transference to milk or eggs or its utilization for work, it is necessary to take into account the heat production incidental to the consumption of the food. For this reason the term 'net energy' or 'starch equivalent', as it is termed in Britain, which takes this heat production into account, is superior to expressions of energy value in terms of 'digested energy' or 'metabolizable energy'. Methods of determining net energy were then considered, and slides were shown illustrating the various types of respiration calorimeter in use in different parts of the world. The difficulties involved in interpreting the older calorimetric observations made with cattle and sheep, and indeed those at present being made by Blaxter and Graham at the Hannah Institute, were then considered. The effect of plane of nutrition and the type of basal ration used was discussed, and the fact that very small analytical and instrumentel errors become greatly magnified by the very nature of the differential methods of computing the results was emphasized. Blaxter and Graham showed that, though well-known text-books and feeding-stuff tables quote energy values of some 250-300 foods, sixty years of work at Möckern experimental station in Germany, where almost all this work has been done, deal with but thirty-seven foods in seventy-one experiments. Most of the values in the tables are therefore computed values, and recent work has shown that the accuracy of these estimations is frequently very low. Finally, Blaxter and Graham deplored the tendency of workers in this field during the past fifty years-admittedly with a few exceptions- - to become involved in many points of minor importance and to spend much time on what is nothing more than arithmetical re-expression of the results obtained by Kühn, Kellner and Armsby without contributing in any way to a deeper know. ledge of the subject. They regard it as imperative that an end should be put to recalculating Kellner's results of 1900-5 and that emphasis should be placed on new experiments carried out in the light of modern knowledge of intermediary metabolism and with modern equipment.

The discussion was continued in a second paper by Dr. J. C. D. Hutchinson (Poultry Research Centre, Edinburgh), who dealt with the reasons why there has been so little progress in assessing the energy value of feeding-stuffs in spite of the great scientific, economic and practical importance of the subject. He referred to the great difficulties involved and the slowness of this type of work, and cited experience with the Danish calorimeter for cattle with which he is personally acquainted, where the output over a long period averages one result per worker per year. Dr. Hutchinson referred to some ways in which a greater output could be obtained-by adopting more automatic methods of measuring heat loss, by dispensing with the necessity of simultaneous estimates of carbon, nitrogen and energy retention and possibly by using methods involving carcase analysis or bodywater determinations. $\mathrm{He}$ agreed with Blaxter and Graham that a more fundamental approach with less of the empiricism that has necessarily characterized the earlier work would prove most profitable in the future.

In the afternoon session Dr. E. M. Widdowson (University of Cambridge) mentioned that, until the Second World War, the energy values of food for man appeared to be of interest chiefly to compilers of food composition tables; but early in the War it was found that calorie calculations made on the two sides of the Atlantic did not agree, and this led to a better realization of the great practical importance of the subject. Dr. Widdowson discussed several tables of food composition published during the past fifty 